\title{
Antibiotics / anti-inflammatories for reducing acute inflammatory episodes in lymphoedema of the limbs (Review)
}

Badger CMA, Preston NJ, Seers K, Mortimer PS

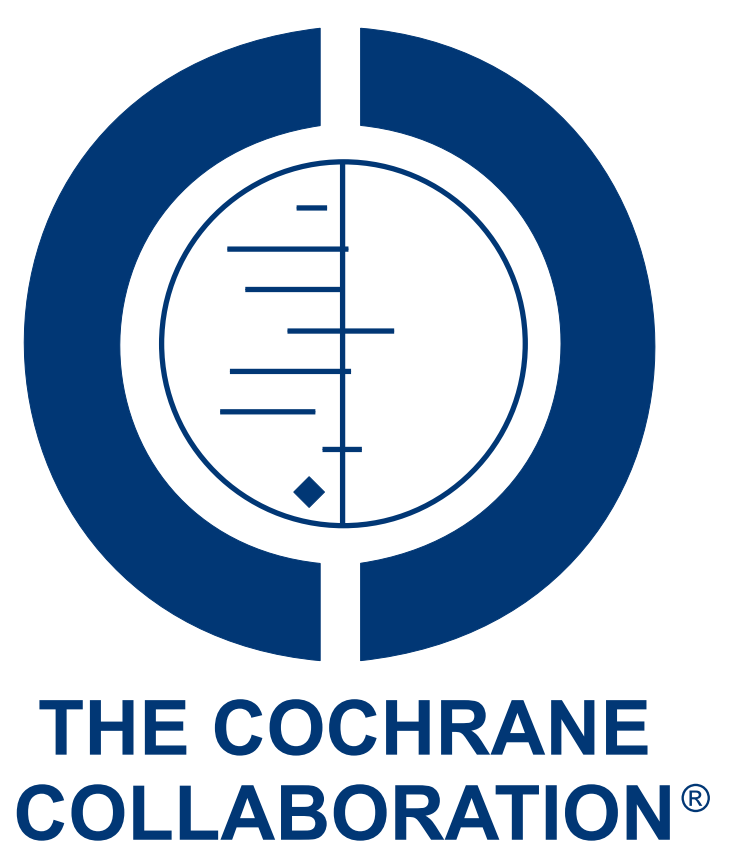

This is a reprint of a Cochrane review, prepared and maintained by The Cochrane Collaboration and published in The Cochrane Library 2009, Issue 1

http://www.thecochranelibrary.com

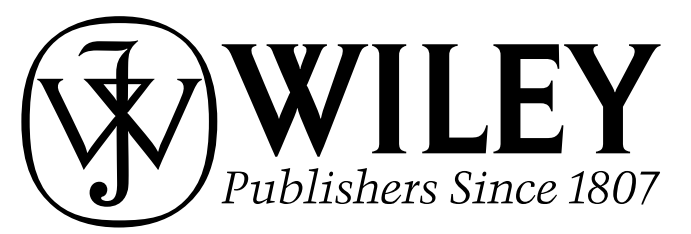

Antibiotics / anti-inflammatories for reducing acute inflammatory episodes in lymphoedema of the limbs (Review)

Copyright (C) 2009 The Cochrane Collaboration. Published by John Wiley \& Sons, Ltd. 
TABLE OF CONTENTS

HEADER . . . . . . . . . . . . . . . . . . . . . . . . . . . . . . . . . . . . . . . 1

REASON FOR WITHDRAWAL . . . . . . . . . . . . . . . . . . . . . . . . . . . . . . . . . . . $\quad$.

WHAT'S NEW . . . . . . . . . . . . . . . . . . . . . . . . . . . . . . . . . . . . . 1

HISTORY . . . . . . . . . . . . . . . . . . . . . . . . . . . . . . . . . . . . . . . . 1

SOURCES OF SUPPORT . . . . . . . . . . . . . . . . . . . . . . . . . . . . . . . . . . . . . . . . . . 2 


\title{
Antibiotics / anti-inflammatories for reducing acute inflammatory episodes in lymphoedema of the limbs
}

\author{
Caroline M A Badger ${ }^{2}$, Nancy J Preston ${ }^{1}$, Kate Seers ${ }^{1}$, Peter S Mortimer ${ }^{3}$ \\ ${ }^{1}$ Research Team, RCN Institute, Oxford, UK. ${ }^{2}$ Institute Research Team, Royal College of Nursing Institute, London, UK. ${ }^{3}$ Division \\ of Physiological Medicine, Cardiac and Vascular Sciences, St Georges Hospital Medical School, London, UK \\ Contact address: Kate Seers, Research Team, RCN Institute, Radcliffe Infirmary, Woodstock Rd, Oxford, OXON, OX2 6HE, UK. \\ kate.seers@rcn.org.uk.
}

Editorial group: Cochrane Breast Cancer Group.

Publication status and date: Withdrawn from publication for reasons stated in the review, published in Issue 1, 2009.

Review content assessed as up-to-date: 29 September 2003.

Citation: Badger CMA, Preston NJ, Seers K, Mortimer PS. Antibiotics / anti-inflammatories for reducing acute inflammatory episodes in lymphoedema of the limbs. Cochrane Database of Systematic Reviews 2009, Issue 1. Art. No.: CD003143. DOI: 10.1002/14651858.CD003143.pub3.

Copyright @ 2009 The Cochrane Collaboration. Published by John Wiley \& Sons, Ltd.

The editorial group responsible for this previously published document have withdrawn it from publication.

\section{REASON FOR WITHDRAWAL}

This review is withdrawn Issue 1, 2009. The authors of this review have declined to update this further and the conclusions are not relevant to breast cancer clinical practice

\section{WHAT'S NEW}

Last assessed as up-to-date: 29 September 2003.

23 October 2008 Amended Converted to new review format. 


\section{H I S T O R Y}

Protocol first published: Issue 3, 2001

Review first published: Issue 2, 2004

17 February 2004 New citation required and conclusions have changed Substantive amendment

\section{SOURCES OF SUPPORT}

\section{Internal sources}

- Royal College of Nursing, UK.

\section{External sources}

- No sources of support supplied 